\title{
Hospital-Based Case Series Analysis of Road Traffic Trauma Patients in Sri Lanka
}

\author{
M. A. C. Lakmal ${ }^{1,2}$ - E. M. D. N. K. Ekanayake ${ }^{1}$ - S. H. P. Kelum ${ }^{1}$ - B. D. Gamage ${ }^{1}$ J. A. S. B. Jayasundara ${ }^{1,3}$ (1)
}

Received: 26 September 2019 / Accepted: 12 June 2020 / Published online: 17 June 2020

(C) Association of Surgeons of India 2020

\begin{abstract}
Road traffic accidents claim many lives each year worldwide and cause significant disability among survivors. Resulting socioeconomic burden is severe in low- and middle-income countries. Global emphasis currently focuses on trauma education and prevention in addition to improving post-injury care. Sri Lankan government recently made compulsory legislation to improve the safety standards of imported motor vehicles. Such regulations would not directly protect vulnerable road users (VRUs) who form the main bulk of Sri Lankan and South Asian automobile trauma casualties. With the objective of reviewing the management outcome of automobile trauma in order to correlate the potential impact of new legislation on injury prevention, data of all admitted road traffic injury victims were audited for 2 months. Out of 473 eligible cases (332 (70.2\%) - males; mean age 37.2 years), there were 14 (3\%) fatalities. Of 459 (97\%) survivors, 77 (16\%) suffered major injuries. Twelve out of 14 (85.7\%) fatalities, 64 of $77(83.1 \%)$ survivors with major injuries and 263 of $382(68.8 \%)$ cases of lesser injuries were VRUs $(p$ value $=0.02$ : chi-square). VRUs had a significantly higher mean Injury Severity Score (ISS) of $10.96 \pm 8.43$ SD than non-VRUs who had a mean ISS of $8.14 \pm 6.04 \mathrm{SD}(p=0.003: t$ test). Among all survivors, $33 / 39(84.6 \%)$ with permanent disability, $95 / 110$ $(86.4 \%)$ with temporary disability and 199/310 (64.2\%) with no residual disability were VRUs ( $p$ value $<0.0001$ : chi-square). Of 222 drivers/riders, $45(20.3 \%)$ had consumed alcohol prior to the incident and $20(9 \%)$ were driving without a valid licence. Thirty-four out of $162(21 \%)$ motor bike travellers were not wearing a protecting helmet. Results denote that VRUs suffer significant majority of the fatalities and major injuries after road traffic trauma and to have higher residual temporary/permanent disability among survivors. Recent compulsory motor vehicle safety measures are unlikely to directly protect majority of automobile trauma victims in Sri Lanka. To obtain a higher impact on road traffic injury prevention, main emphasis has to be given to improve the safety standards of VRUs in developing countries.
\end{abstract}

Keywords Vulnerable road users · Trauma care $\cdot$ Automobile accidents $\cdot$ Injury prevention

\section{Introduction}

Annually, more than 970 million people would suffer traumarelated injury requiring medical attention, and almost four million of those succumb to their injuries worldwide. Globally, trauma remains the leading cause of death in individuals between 1 and 46 years of age, and is the third leading cause of death overall across all age groups [1]. According to

J. A. S. B. Jayasundara

bingumalj@gmail.com

1 Colombo South Teaching Hospital, Kalubowila, Dehiwala, Sri Lanka

2 National Hospital of Sri Lanka, Colombo, Sri Lanka

3 District General Hospital, Nuwara Eliya, Sri Lanka the World Health Organization (WHO) data, road traffic injuries accounted for more than $40 \%$ of unintentional traumarelated deaths and resulted in 1.4 million estimated deaths in 2016 [2]. Global distribution of automobile trauma-related deaths is heterogeneous and average rate of such fatality is 8.3 per 100,000 population in high-income countries. The value rises three times to reach 27.5 per 100,000 population in low-income countries [3]. According to 2017 World Bank classification, $85 \%$ of global population live in low- or middle-income countries in Southeast Asia, Africa and South America, using $60 \%$ of all vehicles accounting for 93\% of road traffic-related deaths [3]. WHO estimated Sri Lanka to have had 3600 automobile trauma deaths in 2016 which was $2.5 \%$ of all causes of deaths in the country [2]. Road crash injuries would be the third leading cause of disability among survivors by 2030 [3]. Regional road traffic 
trauma fatalities are still on the rise in Africa and Southeast Asia. Furthermore, WHO has identified pedestrians, cyclists, motorcyclists and three-wheeler occupants as vulnerable road users and states such at-risk group to account for more than $80 \%$ of all road traffic trauma deaths in Southeast Asia [3]. It is clear that while developed high-income nations are finding answers to control the pandemic of automobile trauma burden, the rest of middle- and poor-income countries appear to be struggling to find the way out.

Sri Lankan government recently implemented new legislation to prohibit the importation of motor vehicles without seatbelts, air-bags and anti-lock brake systems as a measure of improved vehicle safety [4]. Despite this development being a forward move towards reaching the global best practice measures of vehicle safety, such regulations would have minimal impact on the safety of pedestrians, pedal/motorcyclists and three-wheeler passengers which comprise a large proportion of Sri Lankan and Indian sub-continental road traffic trauma casualty mass. In such a background, descriptive road traffic trauma case analysis was performed at the Accident Service Unit, Colombo South Teaching Hospital (ASU, CSTH), the second-largest trauma centre in Colombo. The objectives were to describe the demographics of the patients, to identify human risk factors associated with the accidents and to review the management outcome of road traffic trauma victims in order to correlate the potential efficacy of new motor vehicle safety legislation on prevention/reduction of such injury causation.

\section{Methods}

In the prospective observational study carried out at the ASU, $\mathrm{CSTH}$, data of all road traffic trauma victims irrespective of injury severity were collected for 2 months from 1 June to 31 July 2018. Any vehicle occupant or a roadside victim suffering injury as a result of a vehicle crashing against another vehicle/property/person/animal and/or as a result of a vehicle toppling itself without a collision were included for the study. Automobile trauma cases that were pronounced dead on admission were included. Any road traffic trauma victim except who was travelling inside the shield of the safety of a doorlocked motor vehicle was considered as a vulnerable road user (VRU). A wide range of road users including pedestrians, riders or pillion riders of motor cycles/scooters, pedal cyclists and three-wheeler drivers/occupants were grouped into this category. Injury Severity Score (ISS) was used to quantify the severity of the suffered anatomical destruction and a score of 16 or above which predicts $10 \%$ mortality was considered as major injury [5]. Data were collected from the hospital notes aided by direct questioning of the patients when needed, during hospital stay. Additional information on injury pattern and cause of death was gathered from forensic autopsy records in fatal cases. Management details about the cases transferred out for neurosurgical procedures or ventilator support to other hospitals were gathered from relevant institutions. Injury severity and outcome results were compared between VRUs and others. Ethical approval for this study was taken from the Ethical Review Committee, CSTH.

\section{Results}

There were 502 road traffic trauma casualty admissions during the study period, out of which 29 cases had to be excluded due to deficient documentation (Fig. 1). Out of 473 considered cases, $332(70.2 \%)$ were males and mean age was 37.2 years (range 4-82 years). Of those, 321 (67.9\%) injured persons were in economically productive age group. There were 14 (3\%) fatalities. Among the survivors, 77 (16\%) patients suffered major injuries with ISS $\geq 16$. Twelve out of $14(85.7 \%)$, 64 of $77(83.1 \%)$ and 263 of $382(68.8 \%)$ cases of fatalities, major injury survivors and less severe injury survivors were VRUs respectively. Within the study cohort, fatalities or survivors with injuries of ISS $\geq 16$ were statistically higher among VRUs ( $p$ value $=0.02$ : chi-square) .

Among the 14 fatalities, eight cases were declared dead on admission and three succumbed within $1 \mathrm{~h}$ from admission. Except for a car driver and a front-seat passenger who died due to polytrauma following high-velocity crashes, the rest of the deaths were in VRUs (3 pedestrians, 7 motorcyclists/ pillion riders, 2 three-wheeler occupants). Within the subcohort of fatalities, isolated craniofacial/cervical spine injuries - 3, craniofacial/cervical spine injuries with polytrauma -5 , haemorrhage due to polytrauma -4 , haemorrhage due to cervical vascular injury - 1 and multi-organ failure due to sepsis - 1 were the causes of death.

Among 77 patients who survived major injury (ISS range 16-45), head or neck-55 (71.4\%), face-18 (23.4\%), chest-28 (36.4\%), abdomen-22 (28.6\%), extremeties-43 $(55.8 \%)$ and external wounds - $44(57.1 \%)$ were the affected body regions in combination or isolation. Severe head, thoracic and abdominal injuries (with Abbreviated Injury Scale $\geq 4$ ) were suffered by $31(40.3 \%), 7(9.1 \%)$ and $5(6.5 \%)$ cases respectively. Main management strategies performed in severely injured survivors and in-hospital fatalities are summarized in Table 1 . There were 364 cases with ISS $<16$ and 187 of them were managed as out-patients. Need for neuroobservation (91), requirement of wound or fracture management under general/regional anaesthesia (59) and observation for abdominal/thoracic trauma (18) were the main causes for in-hospital admission for the cases with less severe injuries. VRUs had a significantly higher mean ISS of $10.96 \pm 8.43 \mathrm{SD}$ than non-VRUs who had a mean ISS of $8.14 \pm 6.04$ SD among all survivors ( $p=0.003$ : unpaired $t$ test). Out of 459 survivors, $33 / 39(84.6 \%)$ with permanent disability, 95/110 
Fig. 1 Summary of injury and disability classification of road traffic trauma victims (VRU vulnerable road user, ISS Injury Severity Score)

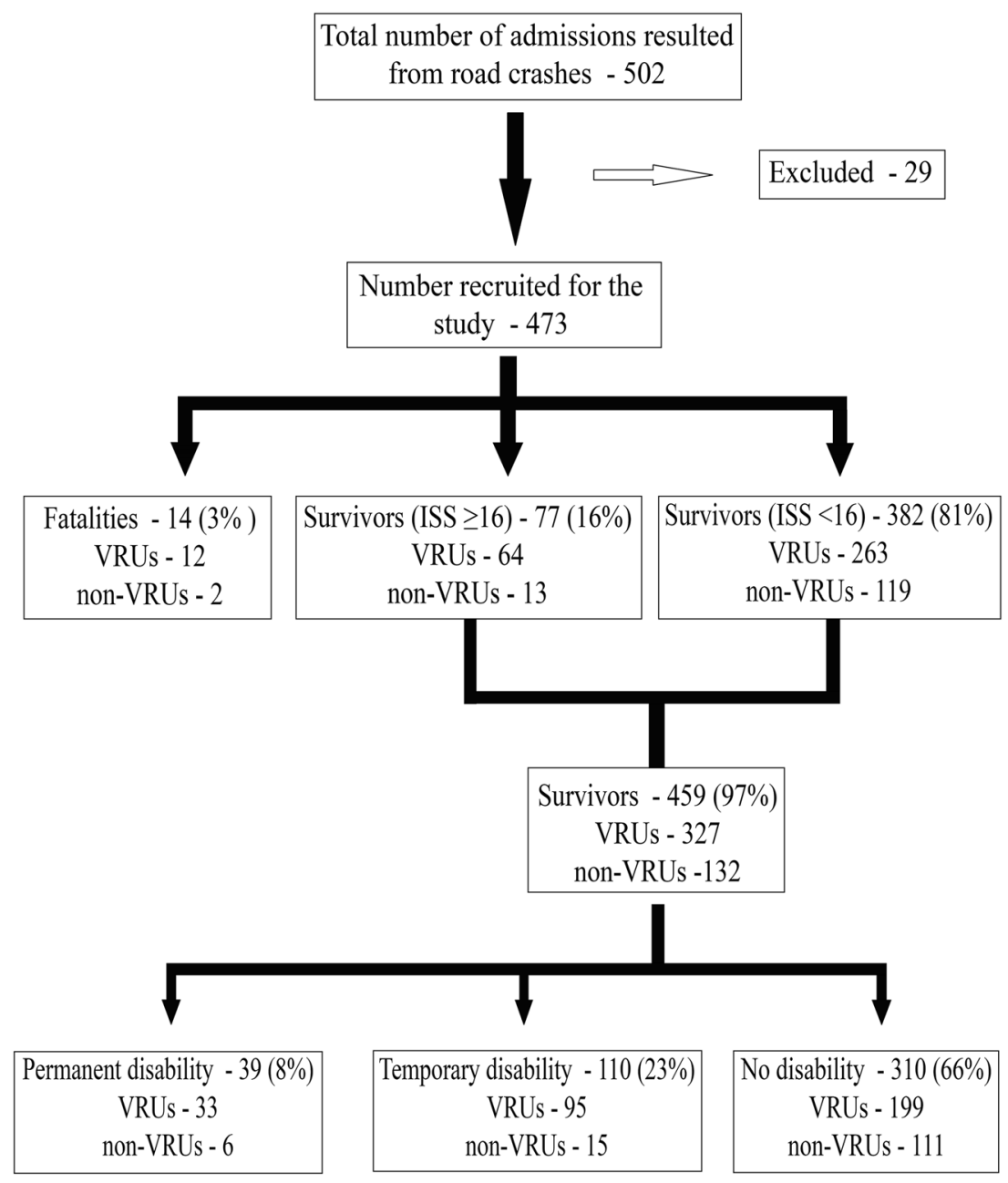

(86.4\%) with temporary disability and 199/310 (64.2\%) with no disability were VRUs. Permanent or temporary disabilities were significantly higher among VRUs ( $p$ value $<0.0001$ : chi-square).

There were 222 were drivers/riders of a vehicle/motorbike/ pedal cycle within survivors. Of those drivers/riders, 45 (20.3\%) admitted consumption of alcohol prior to the incident on subsequent questioning for the study but records were deficient in many cases to determine whether they were 'under the influence of alcohol' or beyond the legal limit. Within the sub-cohort of drivers/riders, $20(9 \%)$ were driving without a valid licence and $61(27.5 \%)$ felt exhausted or asleep at the time of the motor crash. There were 162 motorbike/pedal cycle riders or pillion riders who survived and 34 (21\%) of them were either not wearing a protecting helmet or not properly securing the helmet.
Table 1 Management strategies utilized in cases with ISS $\geq 16$

\begin{tabular}{lr}
\hline Procedure & Number \\
\hline Tracheostomy/cricothyroid puncture & 2 \\
Tube thoracostomy & 20 \\
Laparotomy & 6 \\
Neurosurgical procedures or provision of ventilator support for head injury & 33 \\
Orthopaedic surgical procedures for long bone fractures & 17 \\
Provision of critical care support for organ dysfunction (excluding pure respiratory support) & 4 \\
$\geq$ Three units of blood/blood product transfusion & 8 \\
Maxillofacial surgical procedures & 3 \\
\hline
\end{tabular}

One patient would have had more than one procedure 


\section{Discussion}

The number of deaths happening as a result of road crashes remains unacceptably high, with an estimated 1.4 million people dying each year worldwide. The burden is very severe in low-income countries $[2,3]$. Substantial proportion of survivors suffer temporary or permanent disability and negatively affect the labour force of a country. Lost workforce due to mortality or morbidity of victims and loss of productivity of the affected family members add to the financial burden caused by automobile accidents/trauma during pre-hospital and hospital treatment phases and post-hospital rehabilitation [6]. Therefore, global emphasis on current day trauma management focuses on trauma education and prevention in addition to improvements in the post-incident care using trauma systems $[1,7]$. Haddon matrix has described both protective and vulnerable components of human, vehicle-related and environmental factors leading to a road traffic crash. It details such mechanisms during pre-crash, crash and post-crash phases $[1,8]$. Current day emphasis is made to understand how such domains can be modified to minimize injury and death. Vehicle safety features such as airbag protection, shatter-resistant windshields and proximity warning alarm systems are important protective domains in reducing injury severity during motor traffic collisions. Environmental safety measures like improved lighting on roadways, implementation of strict motorbike helmet/seatbelt/child restrain laws and enforcement of speed limits are important injury prevention initiatives that have saved thousands of lives. In addition, legislation against the use of electronic devices during driving and against drink-driving is important to modify human risk factors during the pre-crash phase [1,3].

Several previous studies have audited management outcomes and associations of road traffic trauma in Sri Lanka [9-14]. The current study provides the data from the secondlargest trauma centre in Colombo. There are several eyeopeners arising from this review. The demographic description of this study denotes male predominance among all trauma victims irrespective of the injury severity. Road traffic trauma in general had undesirably affected the economically productive age group between 20 and 60 years than the rest in this study population. Such permanent or temporary reduction of the country's workforce would generate an immensely negative impact on the socioeconomic status of the individual, family and the country as a whole. Secondly, while reviewing the common human risk factors contributory to automobile trauma, this study shows that among surviving drivers, at least one in five had consumed alcohol leading into the event and one in ten was driving/riding without eligibility, thus committing criminal offences. One in five surviving motorcycle travellers had not worn the helmet at the time of the crash and reasons for such irresponsible risk-taking human behaviour is beyond explanation. Previous Sri Lankan studies also show similar rates of human risk-taking behaviour or negligence and it is disheartening to see such high negative rates being continued without improvement over two decades [9, 11, 14]. General observation is that such hazard patterns not only appear to be confined to Sri Lanka but also seem to be a common concern to Southeast Asia and Africa. Several recent studies from India also have provided adequate evidence to prove the gravity of this concern [15-20]. Legislation and public awareness should go hand in hand to minimize such human risktaking behaviour.

The highlight of the study is that more than $70 \%$ of the total study population of road traffic trauma victims suffering injuries of any severity had been VRUs travelling in unprotected two/three-wheeled motor vehicles or on foot. Within the study cohort, significant majority of the fatal and potentially fatal major injuries were suffered by the VRUs. Among survivors, significantly higher proportion of VRUs ended up with residual temporary or permanent disability. These important facts provide a clear inference for injury/disability/fatality reduction related to automobile crashes in Sri Lankan setting. It is clear that emphasis has to be made to safeguard VRUs than the others, as they form the significant majority of the total number of victims, fatalities, potential fatalities and disabilities related to roadside trauma. Essential strict implementation of legislation against alcohol- and drug-related driving offences, emphasis on lane driving with separate cycle tracks and bus lanes, provision of safety kerbs and protected road crossings for pedestrians and stern implementation of helmet laws for motorcyclists etc. appear to be important domains needing urgent attention of stakeholders. Educating the public on these concerns with special emphasis on youth would also be an important aspect during a sustainable automobile injury prevention process. In trauma care literature coming from developed countries, the emphasis is given to further enhance the safety standards of motor vehicles with already established safety modalities as their main vehicle load is formed by such motor vehicles. However, in South Asian countries like Sri Lanka where the majority of the vehicle traffic is formed by pedal/motor bicycles and three wheelers than motor vehicles, emphasis needs to be given to upgrade the safety issues of such vehicles in order to safeguard a major portion of automobile trauma victims.

Literature on trauma management outcome from the neighbouring country India has shown that overall survival outcome following trauma to be substandard in their settings, when compared to the expected norms laid in the western world [21, 22]. Severity of injuries suffered and unexpected deaths reported in their cohorts have been significantly high leading to poor survival outcomes. Inadequacy of resources for trauma care including insufficiencies in manpower and infrastructure have been identified as important reasons for the suboptimal care and end results. Lack of national trauma registries to define the nature of the problem leading to 
deficiencies in policy planning has been contributory to such poor outcomes [22]. Similar comparisons of Sri Lankan trauma management outcomes against the reference standards developed in high-income countries have never been performed before. It is most likely to be in line with the results from the subcontinent due to similarities in the socioeconomic and demographic background further aided by infrastructural and human resource deficiencies. Lack of standardized and validated trauma systems appear to be an important factor determining the indifferent trauma care outcomes in both countries. Profile of injuries, socio-demographics of victims, postincident management and overall outcome following trauma appear to be clearly different in the developing world compared to high-income countries. Identification of the different nature of road traffic trauma pattern in a developing country like Sri Lanka is an important aspect in addressing this problem. In the absence of a centralized trauma registry, multicenter data collection at least by research groups or institutions is vital in order to identify the causative and associated factors leading to road crashes. Such data would suggest the efficacy of current legislation, vehicle and road safety measures and identify the deficiencies needing rectification in Sri Lankan setting. Conclusions arrived from such scientific reviews should guide the amendments in law.

Variable management options had to be utilized for these victims who have suffered potentially fatal major injuries depending on the injury pattern. In addition, great deal of health care resources had to be used during the management of less severely injured cases as well. Burden created on health economics of the country by road crash victims is beyond the scope of this study. It was evident that majority of the fatalities were pronounced dead on admission or succumbed during initial trauma resuscitation. This raises a concern about the need for primordial prevention strategies to minimize such injuries by uplifting safety standards of human, vehiclerelated and environmental factors during pre-crash and crash phases, and then by raising the standards of pre-hospital care during post-crash phase. Recently amended legislation on mandatory motor vehicle safety standards would be a good move for primordial prevention of automobile trauma-related injury or deaths of motor vehicle travellers. However, when the result of this study is extrapolated, it is doubtful whether such regulations would have a massive protective impact on the injury severity of the overall Sri Lankan road traffic trauma casualty load as two-thirds of it is formed by VRUs.

\section{Conclusion}

In Sri Lankan setting, the enhanced safety standards of motor vehicles would only be strengthening the safety of already 'somewhat' protected minority of road users travelling in motor cars while majority of VRUs on foot or 2-3 wheelers are still left unprotected. Several previous studies from Sri Lanka have suggested the need to lessen the load of VRUs by reducing the number of 2-3 wheelers on the road $[10,14,23]$. Multifactorial complex socioeconomic concerns appear to have superseded suggested injury prevention strategies in low/middle-income countries like Sri Lanka. Thus, it is the duty of all stakeholders to take needed action to improve the safety standards of the VRUs on road to make a better impact on overall injury/death prevention related to road traffic trauma especially in developing world including Sri Lanka in addition to improving the motor vehicle safety. Development of a national trauma registry to understand the nature and the severity of the local problem, measures to reduce the number of VRUs by restricting the importation of such vehicles, strict legislation and public awareness to improve the safety of VRUs are important steps in road traffic trauma-related injury prevention in Sri Lanka, in addition to improving the standards of pre-hospital and in-hospital trauma care.

\section{Compliance with Ethical Standards}

Ethical approval for this study was taken from the Ethical Review Committee, CSTH.

Conflict of Interest The authors declare that they have no conflict of interest.

\section{References}

1. Sidwell R, Matar MM, Sakran JV (2017) Trauma education and prevention. Surg Clin N Am 97(5):1185-1197

2. World Health Organization. Global burden of disease. Health statistics and information systems. Disease burden and mortality estimates: Cause-Specific Mortality, 2000-2016. https://www.who.int/ healthinfo/global_burden_disease/estimates/en/ Accessed and downloaded on 6 th June 2019

3. World Health Organization. Violence and Injury Prevention. Global status report on road safety $2018 \mathrm{https} / / \mathrm{www}$.who.int/ violence_injury_prevention/road_safety_status/2018/en/ Accessed and downloaded on $6^{\text {th }}$ June 2019

4. The Gazette of the democratic Socialist Republic of Sri Lanka Extraordinary (Number 2079/70 dated 13th July 2018): Import \& Export Control Development - Notify the Imports \& Exports (Control) Regulation No. 2 of 2018. Available at http://www. imexport.gov.lk/index.php/en/downloads/gazette.html. Accessed and downloaded on $12^{\text {th }}$ June 2019

5. Boyd CR, Tolson MA, Copes WS (1987) Evaluating trauma care: the TRISS method. J Trauma 27(4):370-378

6. Wesson HKH, Boikhutso N, Bachani AM, Hofman KJ, Hyder AA (2014) The cost of injury and trauma care in low and middleincome countries: a review of economic evidence. Health Policy Plan 29(6):795-808

7. Pigneri DA, Beldowicz B, Jurkovich GJ (2017) Trauma systems: origins, evolution, and current challenges. Surg Clin N Am 97(5): 947-959

8. Haddon W Jr (1972) A logical framework for categorizing highway safety phenomena and activity. J Trauma 12(3):193-207 
9. Pathirana AA, Senaratne JW, Sheriffdeen AH (1997) A study of 100 bicycle accidents. Ceylon Med J 42(4):205-206

10. de Silva M, Nellihala LP, Fernando D (2001) Pattern of accidents and injuries involving three-wheelers. Ceylon Med J 46(1):15-16

11. Jeepara P, Pirasth S (2011) Road traffic accidents in eastern Sri Lanka: an analysis of admissions and outcome. Sri Lanka J Surg 29(2):72-76

12. Weerawardena WAK, Illanagasingha TDB, Piyadasa IJ (2013) Analysis of patients admitted with history of road traffic accidents to surgical unit B Teaching Hospital Anuradhapura, Sri Lanka. Anuradhapura Med J 7(1):2-5

13. Edirisinghe PA, Kitulwatte ID, Senarathne UD (2014) Injuries in the vulnerable road user fatalities; a study from Sri Lanka. J Forensic Legal Med 27:9-12

14. Fernando DM, Tennakoon SU, Samaranayake AN, Wickramasinghe M (2017) Characteristics of road traffic accident casualties admitted to a tertiary care hospital in Sri Lanka. Forensic Sci Med Pathol 13(1):44-51

15. Hadaye RS, Rathod S, Shastri S (2020) A cross-sectional study of epidemiological factors related to road traffic accidents in a metropolitan city. J Family Med Prim Care 9(1):168-172

16. India State-Level Disease Burden Initiative Road Injury Collaborators (2020) Mortality due to road injuries in the states of India: the global burden of disease study 1990-2017. Lancet Public Health 5(2):e86-e98

17. Rohilla RK, Kumar S, Singh R, Devgan A, Meena HS, Arora V (2019) Demographic study of orthopedic trauma among patients attending the accident and emergency department in a tertiary care hospital. Indian J Orthop 53(6):751-757

18. Pal R, Ghosh A, Kumar R, Galwankar S, Paul SK, Pal S, Sinha D, Jaiswal AK, Moscote-Salazar LR, Agrawal A (2019) Public health crisis of road traffic accidents in India: risk factor assessment and recommendations on prevention on the behalf of the academy of family physicians of India. J Family Med Prim Care 8(3):775-783

19. Radjou AN, Kumar SM (2018) Epidemiological and clinical profile of fatality in vulnerable road users at a high-volume trauma center. $\mathrm{J}$ Emerg Trauma Shock 11(4):282-287

20. Mitra S, Sarkar AP, Saren AB, Haldar D, Saha I, Sarkar GN (2018) Road traffic injuries: a study on severity and outcome among inpatients of a tertiary care level hospital of West Bengal, India. J Emerg Trauma Shock 11(4):247-252

21. Goel A, Kumar S, Bagga MK (2004) Epidemiological and trauma injury and severity score (TRISS) analysis of trauma patients at a tertiary care centre in India. Natl Med J India 17(4):186-189

22. Deshmukh VU, Ketkar MN, Bharucha EK (2012) Analysis of trauma outcome using the TRISS method at a tertiary care centre in Pune. Indian J Surg 74(6):440-444

23. Dharmaratne SD, Jayatilleke AU, Jayatilleke AC (2015) Road traffic crashes, injury and fatality trends in Sri Lanka: 1938-2013. Bull World Health Organ 93:640-647

Publisher's Note Springer Nature remains neutral with regard to jurisdictional claims in published maps and institutional affiliations. 